\title{
News and Announcements
}

\section{REDI or Not . .}

"Public Libraries and the Remote Electronic Delivery of Information (REDI)," a working meeting, was held in Columbus, Ohio, on Monday and Tuesday, March 23 and 24, 1981. The meeting, jointly sponsored by the Public Library of Columbus and Franklin County (Ohio) and OCLC, Inc., considered the issues that public libraries must examine before becoming involved in electronic information services. Subjects explored included technology, communications, information providers, information users, social implications, and financial, legal, and regulatory responsibilities.

Tom Harnish, program director of OCLC's Home Delivery of Library Services Program, was moderator of the twoday event. Participants at the conference represented a variety of public libraries from throughout the U.S., including New York, Georgia, Texas, California, Colorado, and Illinois. Don Hammer represented LITA at the meeting; Mary Jo Lynch of the ALA Office for Research also attended.

"Geographic distances," said Harnish, "were the only points of separation among the meeting participants. There was an overwhelming agreement on the concerns for the future of libraries and universal access to information in the electronic age."

On the second day of the conference it became apparent that the REDI agenda could not be properly dealt with in two days. "We need an organization which will address these issues on an ongoing basis," said Richard Sweeney, executive director of PLCFC. "Librarians at the conference agreed to promote and lead the development of the electronic library. To that end, this group is seeking recognition by ALA as a membership initiative group with a special interest in the electronic library."
The group's founders prepared the following mission statement for the membership initiative group:

To ensure that information delivered electronically remains accessible to the general public, the electronic library association shall promote participation and leadership in the remote electronic delivery of information* (REDI) by publicly supported libraries and nonprofit organizations.

Goals of the organization are to:

- identify services and information that are best suited to remote electronic delivery;

- plan, fund, and develop working demonstrations of library REDI services;

- communicate the availability of electronic library services to the user community;

- inform the library profession of trends, specific events, and future directions of REDI;

- create coalitions with organizations in allied fields of interest.

Public libraries and nonprofit organizations with information interests, such as information and referral groups, are invited to join the electronic library association. The group plans to meet at the ALA Annual Conference in San Francisco. Meeting details will be announced as soon as they are available.

It was the goal of the "Public Libraries and the Remote Electronic Delivery of Information" meeting to provide the framework within which to address the myriad issues in REDI. The electronic library group will validate the role of libraries in technology. . . REDI or not here we come.

*Information delivered electronically where and when it is needed, in the library and elsewhere (home/office/off-site). 


\section{ARL Adopts Plan for Improving Access to Microforms}

A plan aimed at improving bibliographic access to materials in microform by building a nationwide database of machinereadable records for individual titles in microform sets was approved in principle by the ARL Board of Directors on January 30,1981 . The plan concentrates on monograph collections, and is aimed at providing records for individual titles in both current and retrospective sets. Records added to the database will also aid cooperative efforts in preservation microfilming.

Elements of the plan include:

- inputting of records conforming to accepted North American standards to the major bibliographic utilities by libraries and microform publishers;

- development of "profile matching" by the bibliographic utilities permitting the cataloging of all individual titles in a series or microform collection with single operation;

- cooperative cataloging of current and retrospective microform sets by libraries and publishers;

- compensation for publishers who input acceptable bibliographic records to the bibliographic utilities to offset loss of revenue from card set sales.

Cooperation among libraries, publishers, networks, and others has been stressed throughout the development of the plan, and initiatives on a number of fronts are necessary and encouraged in order to accomplish the goal of improved bibliographic access to microforms. ARL will seek outside funding for a program coordinator to facilitate implementation of the elements outlined above, and recruitment for the one-year position will begin shortly. The coordinator, advised by a committee of librarians (from ARL and non-ARL institutions) and microform publishers, will work with libraries, publishers, and the bibliographic utilities to help get the plan off the ground.

The plan is the result of a one-year study funded by a grant from the National Endowment for the Humanities and conducted for ARL by Richard Boss of In- formation Systems Consultants, Inc. During the course of the year, he interviewed librarians, microform publishers, representatives of the bibliographic utilities, and others interested in bibliographic access to microforms, gradually building the plan from elements on which there was agreement and discarding ideas that were not widely accepted. The effort to build a consensus among the various interested parties was aided by the advisory committee, comprising both ARL librarians and microform publishers, which assisted and advised throughout the course of the project. ARL will publish the study this spring.

ARL sponsorship of this project and its follow-up reflects the long-standing commitment the association has had to improving access to microforms. Two earlier ARL studies on improving bibliographic access contributed to the development of standards for descriptive cataloging of microforms, reinforced the importance of microforms for preserving and disseminating scholarly materials, and identified some of the problem areas that the current study has addressed. Today, as the amount of materials in microform in ARL libraries continues to grow-ARL libraries hold more than $146,660,000$ units of microform-improving access to these materials has taken on even greater urgency.

The Association of Research Libraries is an organization of major research libraries in the United States and Canada. Members include the larger university libraries, the national libraries of both countries, and a number of public and special libraries with substantial research collections. There are at present 111 institutional members.

\section{Battelle Studies Using Computers to Access Unpublished Technical Information}

Engineers may be able to use computers to store, call up, and otherwise display some technical information not currently published in professional journals as a result of a study recently begun by Battelle's Columbus Laboratories.

In a four-month study sponsored by the 
American Society of Mechanical Engineers (ASME), Battelle researchers are examining ways to use computers as an alternative to publications for communicating with the technical community.

ASME is a technical and educational organization with a membership of 100,000 individuals, including 17,000 student members. It conducts one of the largest technical publishing operations in the world, which includes codes, standards, and operating principles for industry.

According to Battelle's Gabor J. Kovacs, certain types of information traditionally are not covered in monthly or quarterly technical journals, yet they often have widespread appeal among engineers.

"Recent advances in computer and telecommunications technologies, coupled with rapidly rising publication costs and postal rates, have created an ideal environment for organizations to consider using computers as an alternative mode of communication," Kovacs said. "Data bases can be used to maintain information that is impractical for conventional publication, and it is now possible to use them for many other types of communication as well."

During the study, researchers will determine the feasibility of using a computer database to disseminate to ASME members such information as short articles dealing with design and applications data, catalog data, and teleconference messages. With the help of the ASME, Battelle specialists will define the information requirements for such a system.

While technology is sufficiently advanced to accommodate virtually any type of information, costs can become prohibitive unless practical compromises are made, Kovacs said. As part of the study, Battelle researchers also will analyze the costs associated with systems of varying capabilities.

Researchers then will define several alternative database systems, which will include such attributes as:

- online, interactive retrieval features

- simple-to-use retrieval language

- user-aid features

- a minimum of seventy-five simultaneous users

- ability to send, store, and broadcast messages

- compatibility with a variety of hard copy and CRTs (cathode ray tube terminals)

- sixteen or more hours per day availability to accommodate different time zones

- a minimum of thirty-characters-persecond transmission rates

Two of these alternative system designs - one representing a minimum capability and the other a maximum capability - then will be selected for further evaluation by Battelle and the ASME. 